\title{
The Ventral Pallidum is Critically Involved in the Development and Expression of Morphine-Induced Sensitization
}

\author{
Amanda L Mickiewicz*, ${ }^{*}$, , Jeanine E Dallimore' and T Celeste Napier ${ }^{2}$ \\ 'Department of Pharmacology and Experimental Therapeutics, Stritch School of Medicine, Loyola University Chicago, Maywood, IL, USA; \\ ${ }^{2}$ Department of Pharmacology, Center for Compulsive Behavior and Addiction, Rush University Medical Center, Chicago, IL, USA
}

\begin{abstract}
Repeated, intermittent exposure to drugs of abuse results in response enhancements to subsequent drug treatments, a phenomenon referred to as sensitization. As persistent neuronal sensitization may contribute to the long-lasting consequences of drug abuse, characterizing the neuroanatomical substrates of sensitization is providing insights into addiction. It is known that the ventral tegmental area (VTA) is necessary for induction, and expression involves the nucleus accumbens (NAc). We reveal here that the ventral pallidum (VP), a brain region reciprocally innervated by the VTA and the NAc, is a critical mediator of opiate-induced behavioral sensitization. Blockade of VP $\mu$-opioid receptors (via intra-VP CTOP injections) negated the ability of systemic administration of the opiate, morphine to induce motor sensitization, and for sensitized rats to subsequently express enhanced responding to a morphine challenge. Intra-VP morphine was sufficient to induce motor sensitization, and this sensitization was expressed following 17 days of withdrawal. Rats with a treatment history of intra-VP morphine demonstrated cross-sensitization to a challenge injection of systemically administered morphine. Conversely, repeated systemic treatments of morphine cross-sensitized to an intra-VP morphine challenge. These results indicate that activation of VP $\mu$-opioid receptors is sufficient to evoke behavioral sensitization and that these receptors are necessary for sensitized responding to systemic morphine. The study pioneers the concept that both development and expression of drug-induced sensitization are regulated by the VP. Thus, the VP is likely an important contributor to neuronal adaptations that underlie addiction.

Neuropsychopharmacology (2009) 34, 874-886; doi:I0.1038/npp.2008. I I ; published online 30 July 2008
\end{abstract}

Keywords: morphine; $\mu$-opioid receptor; opiate; sensitization; cross-sensitization; ventral pallidum

\section{INTRODUCTION}

Repeated intermittent injections of opioids produce an enhancement in motor assessments (sensitization) that become pronounced after a drug-free (withdrawal) period is imposed between the repeated injections and a challenge injection (Babbini and Davis, 1972). The neuronal substrates that accompany motor sensitization in rats are thought to model some processes that persistently plague the drug withdrawn human addict, including the desire to continue to engage in drug-taking. This rationale has spurred considerable interest in ascertaining the neuroanatomical substrates that underlie drug-induced motor sensitization. Consequently, considerable advancements have been made toward understanding the temporal vs spatial relationship for anatomical substrates that drive the induction of behavioral sensitization during repeated drug administration, and the maintenance and expression of

*Correspondence: AL Mickiewicz, Department of Pharmacology, Center for Compulsive Behavior and Addiction, Rush University Medical Center, I735 W Harrison Street, Cohn 422, Chicago, IL 60612, USA, Tel: + I 312563 24I7/2416, Fax: + I 312563 2403, E-mail: amanda_mickiewicz@rush.edu

Received 10 May 2008; revised 28 June 2008; accepted 30 June 2008 these behaviors after the drug is withdrawn. A well-accepted concept largely derived from studies on psychostimulants maintains that glutamatergic inputs to the ventral tegmental area (VTA) consist of a critical synapse for induction (for review, see Wolf, 2002), and this information is transferred by dopaminergic projections to the nucleus accumbens (NAc) where a dopamine-glutamate interaction on medium spiny neurons participates in the maintenance/expression of behavioral sensitization (Li et al, 2003). Though not as thoroughly studied as for psychostimulants, aspects of this concept have been demonstrated for opioids, where it is clear that the VTA (and not the NAc) is important for the induction of opioid-induced behavioral sensitization (Joyce and Iversen, 1979; Vezina and Stewart, 1984; Vezina et al, 1987).

Activation of the VTA and NAc also engages numerous affiliated regions before the execution of motor responding. One such structure, the ventral pallidum (VP), regulates the flow of information to and from the NAc and VTA, as well as inputting the motor outputs of the spinal cord (Zahm, 1989; Mogenson and Yang, 1991). Receiving converging inputs from the VTA dopaminergic neurons (Napier et al, 1991a; Klitenick et al, 1992; Maslowski-Cobuzzi and Napier, 1994; Mitrovic and Napier, 2002) and accumbal opioidergic (and GABAergic) inputs (Zaborszky et al, 1985; Zahm et al, 
1985; Chrobak and Napier, 1993), we predicted that the VP is involved in opiate-induced sensitization. Thus, we revealed that blocking $\mu$-opioid receptors within the VP is sufficient to block the development of sensitized motor responding to systemically administered morphine (Johnson and Napier, 2000). The present series of four experiments further examines the role of the VP in induction, and expands this work to ascertain its role in expression of morphine-induced motor sensitization. To provide a comparison base for the study series, experiment 1 detailed the behavioral profile of the development and persistence of sensitization after systemic administration of morphine in experiments 2-4. Experiment 2 determined that activating $\mu$-opioid receptors within the VP was sufficient to develop behavioral sensitization, and compared the behavioral profile obtained with repeated intra-VP injections of morphine to that obtained during sensitization to systemic morphine. Experiment 3 determined that $\mu$ opioid receptors in the VP were necessary for the long-term maintenance, and subsequent expression of sensitization following a challenge with systemic morphine. Experiment 4 revealed that intra-VP morphine injections cross-sensitized to systemic morphine treatments, and vice versa, to show that sensitized $\mu$-opioid receptor function in the VP contributes to the behavioral sensitization seen with repeated systemic injections of morphine.

\section{MATERIALS AND METHODS}

\section{Animals}

Male Sprague-Dawley rats (Harlan Laboratories Inc. Indianapolis, IN) weighing $225-275 \mathrm{~g}$ on arrival were housed in pairs and acclimated to colony conditions (0700/1900 hours light/dark cycle, temperature maintained at $23-25^{\circ} \mathrm{C}$, with access to rat chow and water ad libitum) for at least 1 week before experimentation. The rats were handled in accord with the procedures established in the Guide for the Care and Use of Laboratory Animals (National Research Council, Washington DC). The specific protocols were approved by the Loyola University Medical Center, Institutional Animal Care and Use Committee.

\section{Drugs}

Systemically administered morphine sulfate (as the salt; Sigma, St Louis, MO; Mallinckrodt, Hazelwood, MO, or the National Institute on Drug Abuse, Bethesda, MD) was dissolved in $0.9 \% \mathrm{NaCl}$ as $10 \mathrm{mg} / \mathrm{ml}$ and administered at a dose of 5 or $10 \mathrm{mg} / \mathrm{kg}$ (i.p.). Controls received an i.p. injection of the $0.9 \% \mathrm{NaCl}$ solution (saline) as $1 \mathrm{ml} / \mathrm{kg}$. Treatments used for intracerebral injections were prepared as follows: saline $(0.5 \mu \mathrm{l}$ per side), morphine $(5 \mu \mathrm{g}$ per $0.5 \mu \mathrm{l}$ per side), the $\mu$-opioid receptor antagonist D-Phe-Cys-TryD-Trp-Orn-Thr-Pen-Thr- $\mathrm{NH}_{2}$ (CTOP; Peninsula Laboratories Inc., Belmont $\mathrm{CA} ; 2.1 \mu \mathrm{g}$ per $0.5 \mu \mathrm{l}$ per side). This antagonist was selected as the naloxone $\mathrm{IC}_{50} / \mathrm{DPDPE} \mathrm{IC}_{50}$ (ie mu/delta ratio) for CTOP is $4800 v s 1300$ for another popular analogue, CTAP (Pelton et al, 1986), and this CTOP dose is similar to those used in previous studies demonstrating alterations in motor- and reward-mediated behaviors in rats (Badiani et al, 1995; Shippenberg and Bals-Kubik, 1995; Johnson and Napier, 2000).

\section{General Protocol for Behavioral Sensitization}

The behavioral sensitization protocol consisted of four phases: (1) baseline: rats were given saline i.p. and/or a sham VP injection (defined below) for 3-8 days and motor activity was quantified (described below), the score obtained on the last day served as baseline activity. (2) Repeated treatment: 1-3 days later, the five, once-daily repeated treatment protocols were initiated. (3) Withdrawal: a 3-, 14-, 17-, or 30-day drug-withdrawal period was imposed. During the last 2-4 days of withdrawal periods that lasted 14 days or more, the rats were again exposed to procedures that emulated the treatment injection, and motor activity was quantified (reacclimation). (4) Challenge: At 1 day after the last reacclimation day, the rats received a morphine challenge injection and motor activity was assessed.

All behavioral measurements were conducted in a dimly lit room with white noise continuously present during the light cycle of the rats using clear plastic 'shoeboxes' $45 \times 24 \times 20 \mathrm{~cm}$ (ie standard housing boxes). Motor activity was quantified by the number of infrared photobeam breaks and tallied by PC computers in 5- or 10-min bins. During the course of the studies, two different monitoring systems were used. One system was built in house, and Basicon microcomputers (Basicon, Beaverton, OR) interphased with a PC counted individual beam breaks (used for experiment 2) from two sets of infrared photocell beams located along the longitudinal axis of the boxes. Two measures were made: (1) a general activity measure that was the total number of photobeam breaks and (2) 'crossings', ie the rat transversing the length of the box, determined by an interruption of either photobeam followed by a beam break at the opposite end of the cage. The other monitoring system (Applied Concepts, Ann Arbor, MI) was fitted with five photobeam pairs placed along the longitudinal axis (used for experiments 1, 3, and 4). The number of beam breaks on this system was totaled from the three inside sets of photobeam pairs, and as in the other system 'crossings' was defined as consecutive interruption of the two sets on the extreme ends of the boxes.

\section{Specific Experiments}

Experiment 1. Profiling morphine-induced behavioral sensitization. A total of 66 rats were used to profile behaviors, using both automated and observation-based collections, in response to a morphine challenge 3-, 14-, and 30 days after the last of five saline or morphine pretreatments. Observer-ranked categories of motoric patterns and overall descriptions of the rats' behaviors were determined for a subset of rats mechanically tested on days 1 and 5 of the repeated treatments and for the challenge test. To do so, two trained observers assigned a motor score for behaviors occurring in $1 \mathrm{~min}$ of every $10 \mathrm{~min}$ during the 90 -min test session. When there was a discrepancy between the two observer numeric scores (which occurred $26 \%$ of the time), an averaged score was used. Descriptors for the scores are as follows: 1-Asleep-like; resting in a head-down curled 
position or lying down with eyes closed. 2-Inactive, resting quietly; lying down but eyes open, with little or no movement. 3-Slow active; intermittent grooming, with infrequent locomotion or rearing/wall climbing. 4-Normal active; explorative-like behaviors, including periodic sniffing, occasional locomotion, rearing/wall climbing. 5Hyperactive; frequent sniffing/licking, locomotion, and/or rearing/wall climbing, typically without a repetitive pattern. 6-Abnormal inactive; frozen stance with protruding eyes, piloerection, Straub tail; but devoid of locomotion; appeared to exhibit a heightened state of awareness, (eg hyperresponsive to normal laboratory sounds). 7-Abnormal and restricted motor activity; category 6 behaviors, with localized locomotion and/or rearing/wall climbing. 8Abnormal with occasional motor activity-category 6 behaviors with infrequent locomotion and/or rearing/wall climbing that is not localized. 9-Intermittent stereotypy; locomotion typically as infrequent 'bouts' or bursts of motor activity in between episodes of frequent licking or paw chewing in between; Straub tail. 10-Fast stereotypy with locomotion; fast licking floor/walls or paw chewing with some locomotion. 11-Fast stereotypy; fast, constant stereotypy with prominent licking and/or paw chewing; devoid of locomotion. For experiments 2-4, the rats' behavior was not observationally quantified; however, trained observers qualitatively noted the general motor behaviors in these rats while were automated collection was occurring.

Experiment 2. Verification that activating $\mu$-opioid receptors in the VP is necessary for morphine-induced behavioral sensitization. To allow direct injection of ligands into the VP, the animals were fitted with guide cannulae overlying the VP. For surgery (conducted 1 week after acclimation to the vivarium), 27 rats were anesthetized with Nembutal $(50 \mathrm{mg} / \mathrm{ml} / \mathrm{kg}$ i.p.; Abbott Laboratories, Chicago, IL) and placed into a stereotaxic apparatus (David Kopf Instruments, Tujunga, CA), with the nosepiece set at $3.3 \mathrm{~mm}$ below the horizontal. Cannulae (23 gauge, $5-\mathrm{mm}$ wide, $15.6-\mathrm{mm}$ long) were lowered into the brain $-0.2 \mathrm{~mm}$ posterior to bregma, $\pm 2.25 \mathrm{~mm}$ off the midline and $-6.3 \mathrm{~mm}$ from dural surface. Four screws were set in the skull and the assembly was secured with dental acrylic.

After cannula implantation, the rats were housed individually and were allowed at least 5 days recovery before beginning the experiments. A separate group of rats served as the nonimplanted controls $(n=10)$; they were double-housed in the same room. Daily, for the next 5 days, the rats were placed into the test box, given a 30-min habituation period, subjected to a sham VP injection procedure (no fluid was injected and injectors that did not protrude beyond the end of the cannula were used) and an i.p. saline injection. Motor activity was assessed for $90 \mathrm{~min}$. The motor scores for the fifth acclimation day were used as baseline activity. After 1 day, the repeated treatment protocol was initiated. The nonimplanted rats were administered morphine $10 \mathrm{mg} / \mathrm{kg}$ i.p. The implanted rats were randomly assigned between two treatment groups: intra-VP CTOP $(2.1 \mu \mathrm{g}$ per $0.5 \mu \mathrm{l}$ per side $)+$ i.p. morphine $(10 \mathrm{mg} / \mathrm{kg})$ or VP sham +i.p. morphine $(10 \mathrm{mg} / \mathrm{kg})$. After 10 days of no treatment, rats were reacclimated for 3 days and on withdrawal day 14 the rats were subject to a treatment challenge either with i.p. morphine or intra-VP CTOP + i.p. morphine.

To allow intracerebral injections, 30-gauge injectors that extended $1.0 \mathrm{~mm}$ beyond the guide cannulae were used. The opposite end of the injectors were connected, via 0.01-mm Tygon microbore tubing (Norton Performance Plastics, Akron, $\mathrm{OH}$ ), to $10-\mu \mathrm{l}$ syringes (Hamilton, Reno, NV) held in a CMA/100 microinjection pump (Carnegie Medicin AB, Stockholm, Sweden). All injections were given to conscious, unrestrained rats and delivered over a 5 -min period at a rate of $0.1 \mu \mathrm{l} / \mathrm{min}$. A $1-\mathrm{mm}$ bubble inserted into the Tygon tubing upon drug loading was required to move $8-12 \mathrm{~mm}$ for an infusion to be considered successful. Following the infusion, injectors were left in place for $1 \mathrm{~min}$ to allow for drug diffusion away from the injector tip.

Experiment 3. Demonstration that injections of morphine into the VP induces behavioral sensitization. To allow direct injection of ligands into the VP, 57 animals were fitted with guide cannulae overlying the VP as described for experiment 2. As a site control, eight additional rats were implanted with cannula targeted to the NAc where the cannulae were stereotaxically lowered into the brain + $1.0 \mathrm{~mm}$ posterior to bregma, $\pm 2.25 \mathrm{~mm}$ off the midline and $-6.0 \mathrm{~mm}$ from the dural surface.

Rats with cannulae targeted to the NAc received a single intra-NAc injection of morphine ( $5 \mu \mathrm{g}$ per $0.5 \mu \mathrm{l}$ per side). Rats with cannulae targeted to the VP were randomly assigned to intra-VP saline $(0.5 \mu \mathrm{l}$ per side), or intra-VP morphine $(5 \mu \mathrm{g}$ per $0.5 \mu \mathrm{l}$ per side) treatment groups. An intra-VP morphine challenge was given after 3 or 17 days of withdrawal (following reacclimation for the latter group).

Experiment 4. Determination of whether there is crosssensitization between behaviors evoked by intraventral pallidal and systemic morphine treatments. To allow intra-VP drug administration, 37 rats were implanted with bilateral cannulae as described for experiment 2. In addition, 26 implanted rats from experiment 3 were also used here. To determine whether VP morphine crosssensitized to systemically administered morphine, two treatment approaches were used. For one, rats were given i.p. morphine $(10 \mathrm{mg} / \mathrm{kg})$ or i.p. saline $(1 \mathrm{ml} / \mathrm{kg})$ for the repeated treatment and intra-VP morphine $(5 \mu \mathrm{g}$ per $0.5 \mu \mathrm{l}$ per side) for the challenge after 14 days withdrawal. For the other, rats were given intra-VP injections of saline $(0.5 \mu \mathrm{l}$ per side) or morphine ( $5 \mu \mathrm{g}$ per $0.5 \mu \mathrm{l}$ per side) for the repeated treatment and after 3- or 14 days withdrawal (with reacclimation procedures provided for the latter), a challenge of i.p. morphine $(5 \mathrm{mg} / \mathrm{kg}$ or $10 \mathrm{mg} / \mathrm{kg})$ was given.

\section{Histology}

After the completion of behavioral testing, cannulated rats were deeply anesthetized with chloral hydrate $(400 \mathrm{mg} / \mathrm{kg}$, i.p.) and pontamine sky blue (Sigma) was injected into the VP. The brains were removed, fresh frozen using dry ice, and cut in $50-\mu \mathrm{m}$ coronal sections. Sections mounted on subbed slides were stained with Pyronin-Y (Sigma). Light microscopy was used to visualize the intracerebral infusion 
site, and the location was agreed on by two treatment-blind observers and reconstructed on a stereotaxic brain map modified from (Paxinos and Watson, 1998).

\section{Statistics}

The following within-treatment group comparisons for the first and last repeated treatment were used to demonstrate development: paired $t$-tests for total session counts or a two-way repeated measures ANOVA for session time $v s$ treatment day, followed by Newman-Keuls test for treatment differences at each time interval in a session. Significance was set a priori at $p<0.025$ according to Bonferroni's rule for multiple comparisons of the same data (ie $\alpha=0.05$ divided by 2). To demonstrate expression, between-treatment groups comparisons of responses to the post-withdrawal challenge were conducted using a two-way repeated measures ANOVA for treatment group vs session time. Post hoc Dunnett's test was used to determine treatment difference from control; a post hoc NewmanKeuls test was used to determine treatment differences at each time interval within a session. Significance was set $a$ priori at $p<0.05$. Data are presented as the mean \pm SEM.

\section{RESULTS}

\section{Experiment 1. Profiling Morphine-Induced Behavioral Sensitization}

To allow identification of the role of the VP in behavioral sensitization induced by systemically administered morphine, it was important to first critically evaluate the response profile to the morphine doses used in this experimental series. We observed that the acute motor effects of single $10 \mathrm{mg} / \mathrm{kg}$ i.p. injection of morphine included an initial period of inactivity with mild catalepsy, followed by activation (Figures 1a-c; refer to day 1 results), as previously reported (Babbini and Davis, 1972). By the fifth once-daily injection of morphine, this profile was notably altered (Figures 1a-c; refer to day 5 ). First, a short period of hyperactivity occurred (captured at the 10-min bin and concluded by $20 \mathrm{~min}$ ) where the number of crossings, total beam breaks, and overall motor score were greater after treatment on day 5 than day 1 . As shown in Figure 1c, a shift occurred from normal exploratory behavior $10 \mathrm{~min}$ after the first morphine dose (ie day 1 score of $4 \pm 0.7)$ to stereotypy interrupted with intense locomotor bursts (day 5 score of $9 \pm 0.5$ ). This profile is thought to reflect tolerance to the motor-depressive effects of morphine (Babbini and Davis, 1972; Babbini et al, 1975; Brady and Holtzman, 1981; Bartoletti et al, 1983; Johnson and Glick, 1993). Photobeam-detected motor activity for 20-60 min post-injection was low for days 1 and 5 (Figures $1 \mathrm{a}$ and $\mathrm{b}$ ), but the underlying behaviors differed. Morphine administration on day 1 induced 'freezing- hypersensitivelike' behaviors (score of $7 \pm 0.6$ ); whereas after day 5 , the rats exhibited intermittent stereotypy (score of $9 \pm 0.4$ ) (Figure 1c). Photobeam-detected motor behaviors occurring for the last $30 \mathrm{~min}$ of the $90 \mathrm{~min}$ post-injection assessment period were enhanced (Figures 1a and b). This locomotor enhancement was strikingly intermittent, and thus was not easily detected in the 1-min assessment periods used for
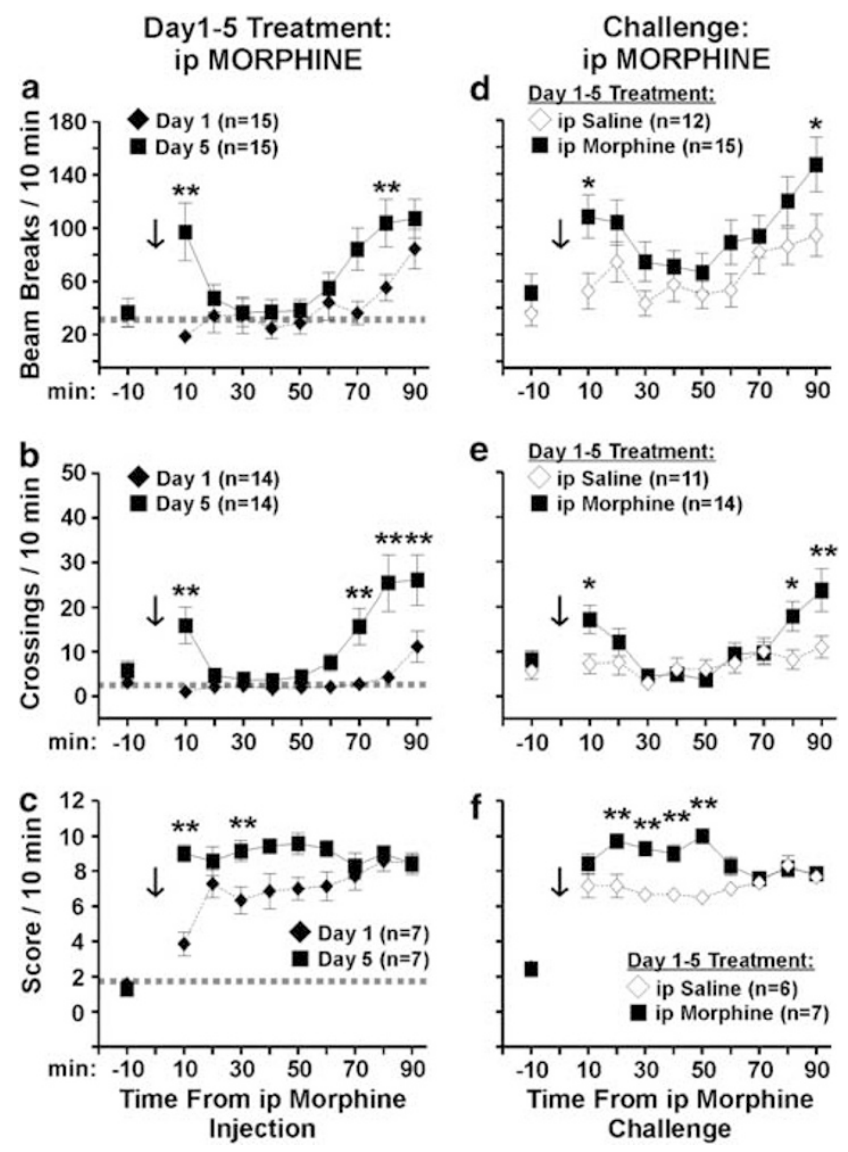

Figure I (Experiment I) Development of motor sensitization to systemically administered morphine. Data are provided in 10-min bins (data also included in Figure 2); arrow indicates time of i.p. injection. Data were subjected to two-way repeated measures ANOVA with post hoc Newman-Keuls. Left column. Day I vs day 5 comparisons. There was no statistical difference between days I and 5 of the saline treatment; these data were averaged and are illustrated by the gray dotted line. (a) Beam breaks. There were significant differences between treatment day $\left(F_{1,28}=5.1, p=0.0318\right)$, across session time $\left(F_{8,224}=10.4, p<0.000 I\right)$, and a treatment-time interaction occurred $\left(F_{8,224}=3.4, p=0.00 \mathrm{II}\right)$. (b) Crossings. There were differences between treatment days $\left(F_{1,26}=15.1\right.$, $p=0.0006)$, across time $\left(F_{8,208}=11.9, p<0.0001\right)$, with a treatment-time interaction $\left(\mathrm{F}_{8,208}=4.9, p<0.000 \mathrm{I}\right)$. (c) Stereotypy score. Differences occurred between treatment days $\left(F_{1,12}=14.0, p=0.0028\right)$, across time $\left(F_{8,96}=2.6, p=0.0127\right)$, with a treatment-time interaction $\left(F_{8,96}=3.7\right.$, $p=0.0007)$. Right column. Expression of motor sensitization after 14 days of abstinence from repeated systemic treatments of morphine as determined by a between-treatment group comparison of the timerelated behaviors exhibited to a morphine challenge $(10 \mathrm{mg} / \mathrm{kg}$ i.p.). (d) Beam breaks. There were no significant differences for treatment group $\left(F_{1,25}=4.0, p=0.0579\right)$, differences were significant across session time $\left(F_{8,200}=6.8, p<0.0001\right)$; there was no treatment group-time interaction $\left(F_{8,200}=1.0, p=0.4666\right)$. (e) Crossings. Although no difference occurred for treatment group $\left(F_{1,23}=2.4, p=0.1381\right)$, significance occurred across session time $\left(F_{8,184}=9.2, p<0.000 \mathrm{I}\right)$ and for a treatment group-time interaction $\left(F_{8,184}=3.6, p=0.0007\right)$. (f) Stereotypy score. Significant differences occurred between treatment groups $\left(F_{1,11}=24.0\right.$, $p=0.0005)$ with no difference across session time $\left(F_{8,88}=1.4\right.$, $p=0.2235)$. Nonetheless, a treatment group-time interaction did occur $\left(F_{8,88}=5.5, p=0.001 \mathrm{I}\right)$. ${ }^{*} p<0.05 ; * * * 0.01$.

observational scoring (compare Figures $1 \mathrm{a}$ and $\mathrm{b}$ with $\mathrm{c}$ ). All behavioral assessments remained stable with repeated saline treatments (data not shown). These results show that motor sensitization developed during the repeated morphine 
administration protocol used here. Figures $1 \mathrm{~d}-\mathrm{f}$ show that the day 5 behavioral time course was similar to that obtained with the morphine challenge; therefore, the response induced during the repeated treatments persisted largely intact. Figure 2 shows the persistence of these behaviors, with sensitized responding to morphine challenge occurring at 3-, 14-, and 30 days of withdrawal.

To assure that the rats undergoing extended (14 or 30 day) withdrawal periods were reacclimated to the testing procedures during the last 2-4 days before the morphine challenge, we used the same protocol employed for the pretreatment baseline. The motor scores obtained for the last reacclimation day were similar to pretreatment baseline levels (paired $t$-test $p$-value ranged from 0.11 to 0.21 ; data not shown). Thus, rats in all withdrawal period groups were similarly acclimated to the test procedure before the challenge was presented. In addition, baseline motor scores were regained with saline treatments in the test environment after repeated pairings of morphine, indicating that the pretreatment habituation period
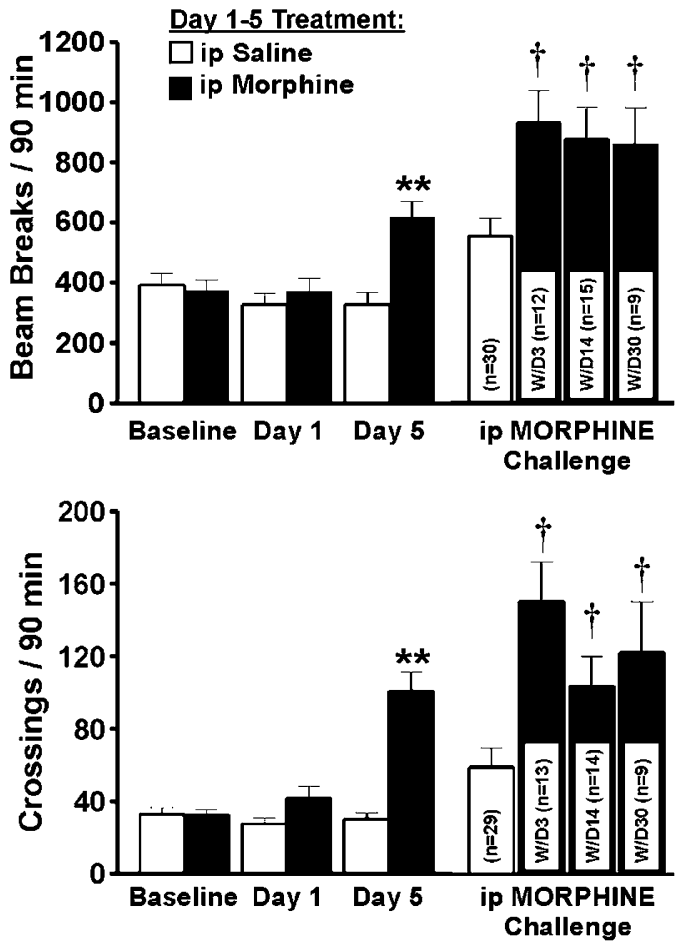

Figure 2 (Experiment I) Persistence of motor sensitization induced by systemic morphine. The total photobeam interruptions tallied for the 90min test period for the last day of pretreatment acclimation (baseline), the first and fifth repeated treatments of saline or morphine $(10 \mathrm{mg} / \mathrm{kg}$; pooled across withdrawal period groups), and following a morphine challenge $(10 \mathrm{mg} / \mathrm{kg})$ administered on withdrawal day (W/D) 3, I4, or 30 are shown. Data from the W/DI4 group are also shown in Figure I. Verifying that sensitization did develop, paired $t$-tests $(* * p<0.0 I)$ between days $I$ and 5 differed with morphine, for beam breaks (top; $t=-3.473, p=0.00 \mathrm{I}$ ) and crossings (bottom; $t=-4.38 \mathrm{I}, p=0.000$ ). Persistence of this effect was demonstrated with a one-way ANOVA for responses to the morphine challenge. Treatment history altered the response to morphine challenge for beam breaks $\left(F_{3,62}=4.9, \quad p=0.004\right)$ and crossings $\left(F_{3,61}=6.3\right.$, $p=0.000$ ). A post hoc Dunnett's test revealed differences between saline-pretreated rats (pooled data) and morphine-pretreated rats for each withdrawal period group $\left({ }^{\dagger} p<0.05\right)$. sufficiently acclimated the rats so that the environment did not impose cues which contributed to the motor effects measured in the absence of morphine. This suggestion is in agreement with our prior work with 3-day withdrawal (Johnson and Napier, 2000) and it was validated with subsequent experiments in the current study.

\section{Experiment 2. Verification that $\mu$-Opioid Receptors in the VP are Necessary for Morphine-Induced Motor Sensitization}

We previously reported that intra-VP injections of the selective $\mu$-opioid receptor antagonist, CTOP, before each daily i.p. injection of morphine blocked the development of behavioral sensitization, and antagonism was not obtained from CTOP injections dorsal to the VP (Johnson and Napier, 2000). We also determined that intra-VP CTOP alone does not alter motor function (Johnson and Napier, 2000). Implanted (Figure 3) and nonimplanted rats that received systemic morphine treatments were pooled for days 1 and 5 (Figures $4 \mathrm{a}$ and b). It is noteworthy that baseline beam breaks for the single-housed implanted rats $(276 \pm 50 / 90 \mathrm{~min}$ test period) were similar to the doublehoused nonimplanted rats $(207 \pm 20$; Student's $t$-test, $p>0.05$ ), as was the response to $10 \mathrm{mg} / \mathrm{kg}$ i.p. morphine on day 1 ( $227 \pm 76$ vs $270 \pm 43$; Student's $t$-test, $p>0.05)$. Also, sensitization developed between days 1 and 5 for both the single-housed implanted rats $(227 \pm 76$ vs $386 \pm 52$; paired $t$-test, $p<0.05)$, and the double-housed nonimplanted rats $(270 \pm 42$ vs $598 \pm 58$; paired $t$-test, $p<0.05)$. Thus, cannulae implantation and housing conditions did not appear to impact motor responding to systemic morphine. The current study corroborated previous findings that intra-VP injections of CTOP blocked the development of sensitization (Figures $4 \mathrm{c}$ and $\mathrm{d}$ ), and extended the prior work to show that sensitized responding to morphine does not return even following 14 days of drug withdrawal (Figure $4 \mathrm{e}$ and $\mathrm{f}$, filled circles).

We also now reveal that the expression of the sensitized response was blocked when intra-VP injections of CTOP preceded the acute i.p. morphine challenge. That is, following 14 days of drug abstinence by rats sensitized to morphine, the ability of a morphine challenge to demonstrate enhanced motor responding is abrogated if the CTOP is injected into the VP $15 \mathrm{~min}$ before the morphine challenge (Figures $4 \mathrm{e}$ and $\mathrm{f}$, filled diamonds). The level of responding following these treatments was similar to that obtained following i.p. saline treatments (compare with Figures $1 a-c$ ) and following the first injection of intra-VP CTOP + i.p. morphine (compare with Figures $4 \mathrm{c}$ and d, day 1 ), and was not to the level obtained following the first i.p. injection of morphine (compare with Figures 1d and e, day 1). These findings suggest that intra-VP CTOP hinders the capacity of the rat to demonstrate motor behaviors engaged by i.p. morphine, whether to a single injection or following development of sensitization.

In summary, $\mu$-opioid receptors in the VP were critically involved in the development of morphine-induced motor sensitization, and a 'breakthrough' or 'recovery' from this effect (due to, for example, an unmasking of extra-pallidal $\mu$-opioid receptors that were sensitized by repeated i.p. morphine) did not occur after 3 days (Johnson and Napier, 

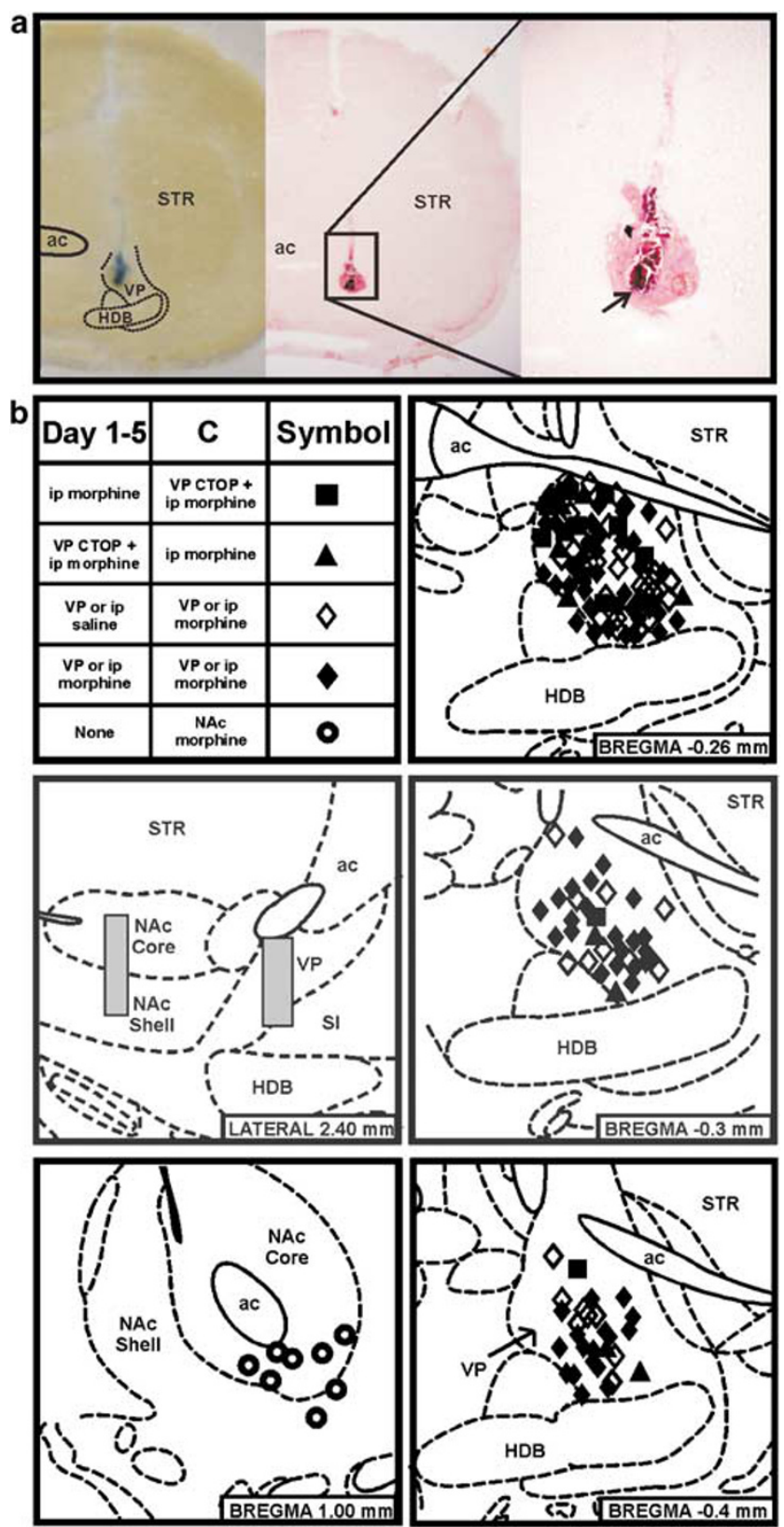

Figure 3 (Experiments 2-4) Injector tip placements within the nucleus accumbens (NAc) and ventral pallidum (VP). (a) Low magnification photomicrograph of a VP coronal section. The left panel shows the unstained slice with pontamine sky blue at the injection site. The middle panel shows the same slice after Nissl staining, illustrating gliosis. The right panel shows the injector tip in the VP under high magnification. Arrow indicates location of the injector tip, filled with pontamine sky blue. This section represents tissue with an indwelling cannula for 30 days. (b) Unilateral representations of bilaterally implanted cannulae were collapsed onto five plates redrawn from Paxinos and Watson (1998). The saggital section $(2.40 \mathrm{~mm}$ from midline) demonstrates the area within the NAc and VP sampled, as detailed in coronal sections. Four different coronal sections relative to Bregma are illustrated. Note that injections within the four VP treatment groups overlapped; ac, anterior commissure; HDB, horizontal limb of the diagonal band; STR, striatum.

2000) or 14 days (current study) of withdrawal. In addition, activation of $\mu$-opioid receptors in the VP was necessary for the expression of motor responses induced by the opiate.
Experiment 3. Demonstration that Injections of Morphine into the VP Induces Behavioral Sensitization

Rats subjected to a single intra-VP injection of morphine ( $5 \mu \mathrm{g}$ per $0.5 \mu \mathrm{l}$ per side) demonstrated increased locomotion, characterized by abrupt hopping and bursts of locomotion, with little stereotypy. This treatment did not produce the initial catalepsy-like behaviors so prominent with $10 \mathrm{mg} / \mathrm{kg}$ i.p. morphine (qualitative observations). Photobeam assessments revealed the following (compare Figures $5 \mathrm{a}$ and $\mathrm{b}$ showing intra-VP morphine with Figures $1 \mathrm{a}$ and b, day 1 showing i.p. morphine): (1) although the maximal score obtained for beam breaks following intra-VP morphine was analogous to that obtained with $10 \mathrm{mg} / \mathrm{kg}$ i.p. morphine, these high scores were obtained much sooner following intra-VP injections. This response profile may reflect the delay for i.p. administered morphine to reach the brain, or that the VP, like the VTA (Joyce and Iversen, 1979; Vezina and Stewart, 1984; Kalivas et al, 1985; Vezina et al, 1987), may not be involved in the cataleptic effects of morphine. (2) VP-treated rats demonstrated less overt locomotion as indicated by the number of times the rats cross lengthwise in the box. The number of crossings induced by the fifth VP morphine injection was slightly elevated over the number obtained with the first VP injections, but this effect was delayed, with significant differences occurring only at 50 and $70 \mathrm{~min}$ post infusion (Figure 5b). Expression of sensitized responding was not observed 3 days after repeated treatments of morphine (Figures $5 \mathrm{c}$ and $\mathrm{d}$ ). However, 17 days after the repeated intra-VP treatments, an enhancement of the motoric effects to a challenge of intra-VP morphine was observed within $5 \mathrm{~min}$ post infusion, and this persisted for $20 \mathrm{~min}$, corresponding to a $77 \%$ change ( $208 \pm 40$ vs $368 \pm 66$; Student's $t$-test, $p<0.05)$ in motor activity during this time period (Figure $5 c$, inset). Such rapid enhanced responding would be expected to occur subsequent to upregulation of $\mu$-opioid receptor function within the local vicinity of the intracerebrally injected site. To verify that the motor effects induced by morphine were not related to the physiochemical structure of the alkaloid, we conducted a pilot study with intra-VP injections of DAMGO, an enkephalin peptide analogue that is a highly selective, full agonist at the $\mu$ opioid receptor. A DAMGO challenge injection $(0.15 \mu \mathrm{g}$ per $0.5 \mu$ per side) was administered 14 days after the last of five once-daily treatments of DAMGO $(0.15 \mu \mathrm{g})$ or vehicle. The opioid challenge increased the number of beam breaks by $108 \%$ in the 20 min following VP infusion in DAMGOsensitized rats compared to DAMGO-naive rats $(322 \pm 76 v s$ $155 \pm 24$; Student's $t$-test, $p<0.05$ ).

In summary, these findings reveal that repeated activation of $\mu$-opioid receptors in the VP were sufficient to induce behavioral sensitization, as indicated by expression of the behavior following protracted (but not short-term) withdrawal. As the persistence time frame for expression did not mirror that revealed when i.p. treatments of morphine were used, additional brain regions likely are involved in the effects of repeated systemic treatments with morphine.

The profile of the opiate-induced motor effects differed between the VP and the NAc (Figure 6), another $\mu$-opioid receptor-expressing limbic region (Moskowitz and Goodman, 1984) that is adjacent to the VP (refer to Figure 4). Costall 

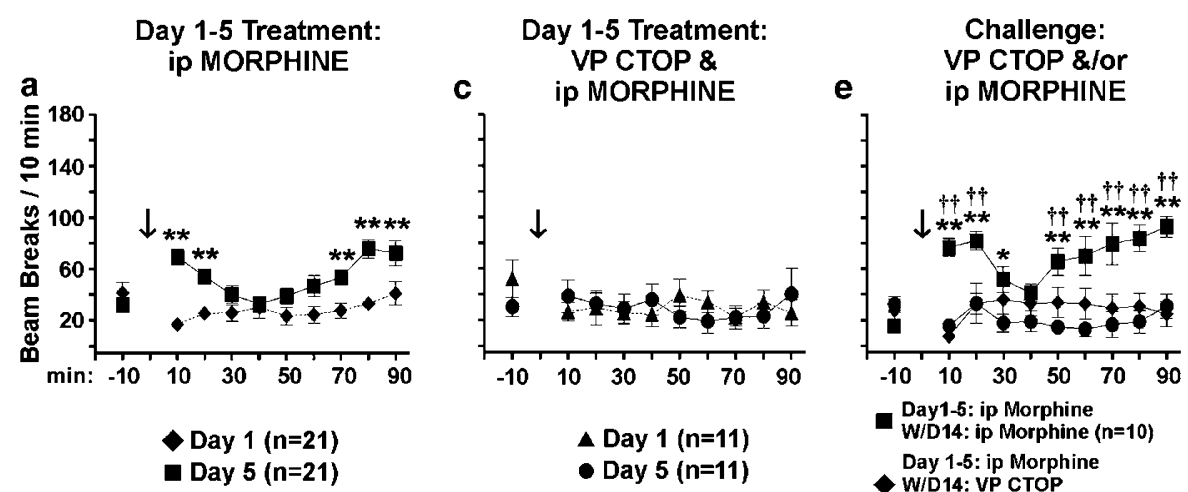

Day1-5: ip Morphine

W/D 14: ip Morphine $(n=10)$

Day 1-5: ip Morphine

W/D14: VP CTOP

\& ip Morphine $(n=12)$
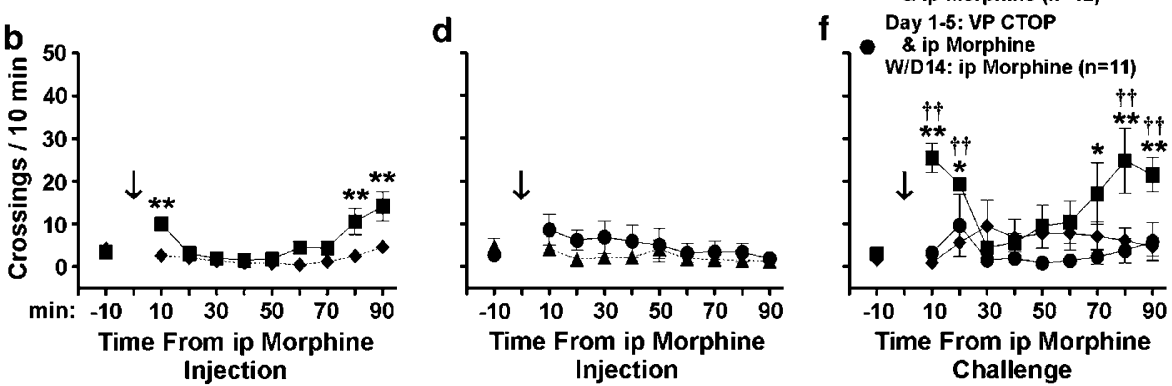

Challenge

Figure 4 (Experiment 2) The $\mu$-opioid receptor antagonist D-Phe-Cys-Try-D-Trp-Orn-Thr-Pen-Thr-NH $H_{2}$ (CTOP) administered to the ventral pallidum (VP) blocked development and expression of sensitization induced by systemic morphine. Data are provided in I0-min bins; arrow indicates time of i.p. injection. A total of 10 rats included in this study were nonimplanted; all others were implanted with guide cannulae overlying the VP. Data were analyzed with a two-way repeated measures ANOVA with post hoc Newman-Keuls. Left column. Development of sensitization with intra-VP sham + i.p. morphine, or i.p. morphine alone. Behaviors exhibited on days I and 5 of the repeated treatment regimen (a) Beam breaks were significantly different for treatment day $\left(F_{1,41}=14.7, p=0.0004\right)$, session time $\left(F_{8,328}=7.4, p<0.000 \mathrm{I}\right)$, and treatment day-time interaction occurred $\left(F_{8,328}=4.7, p<0.000 \mathrm{I}\right) .(\mathrm{b}) \mathrm{Crossings}$ showed significant treatment day $\left(F_{1,39}=8.4, p=0.0061\right)$, session time $\left(F_{8,312}=12.5, p<0.000 \mathrm{I}\right)$, and treatment-time interaction effects $\left(F_{8,312}=4.7\right.$, $p<0.000 \mathrm{I}) * *$ * $<0.0 \mathrm{I}$. Middle column. Intra-VP CTOP $(2.1 \mu \mathrm{g}$ per $0.5 \mu \mathrm{l})$ preceding each repeated i.p. morphine blocked the development of sensitization. There was no significant treatment day, session time, or treatment day-time interaction effects for beam breaks (c) or crossings (d). Right column. CTOP administered into the VP either during development, or immediately before a systemic morphine challenge, blocked the expression of sensitization. For beam breaks $(e)$, there were significant treatment group $\left(F_{2,30}=12.0, p=0.000 I\right)$, session time $\left(F_{8,240}=3.4, p=0.00 \mathrm{I}\right)$, and treatment group-time interaction $\left(F_{16,240}=3.4, p<0.000 \mathrm{I}\right)$ effects. For crossings $(f)$, there were significant treatment group $\left(F_{2,29}=4.4, p=0.0213\right)$, session time $\left(F_{8,232}=3.5\right.$, $p=0.0008)$, and treatment group-time interaction $\left(F_{16,232}=4.4, p<0.000 I\right)$ effects. Specific session time differences between days $I-5$ i.p. morphine/i.p. morphine challenge and days I-5 intra-VP CTOP + i.p. morphine/i.p. morphine challenge; $* 2<0.05 ; * * p<0.0$ I. Specific session time differences between days I-5 i.p. morphine/i.p. morphine challenge and days I-5 i.p. morphine/intra-VP CTOP + i.p. morphine challenge; ${ }^{\dagger \dagger} p<0.01$. (Note that for experiment 2 only, data were collected using locomotor boxes built in house, which resulted in slightly lower scores due to less photocells than the commercial boxes used for experiments I, 3, and 4.)

et al (1978) revealed that intra-NAc injections of $3.25-\mu \mathrm{g}$ morphine induces a biphasic motor response with an initial depression that lasts for $2.5 \mathrm{~h}$ followed by motor enhancements for the next $3 \mathrm{~h}$. This profile predicted our observation that for at least $90 \mathrm{~min}$ after intra-NAc morphine injections $(5 \mu \mathrm{g}$ per $0.5 \mu \mathrm{l}$ per side), the motor scores did not statistically differ from saline controls. This is in stark contrast to intra-VP morphine of the same dose, where a more rapid motor activation was observed (Figure 6). The unique profiles exhibited by intra-VP and intra-NAc morphine injections demonstrate that responding obtained with the intra-VP injection protocol employed did not reflect the drug diffusing into the NAc.

Experiment 4. Determination of Whether there is CrossSensitization Between Behaviors Evoked by Intraventral Pallidal and Systemic Morphine Treatments

Figures $7 \mathrm{a}$ and $\mathrm{b}$ show that repeated infusions of morphine directly into the VP did not induce sensitized responding to a challenge with systemic morphine $(10 \mathrm{mg} / \mathrm{kg})$ following a 3 -day abstinent period. This is illustrated by the similarity in motor profile obtained with these rats (ie filled squares in Figure 7) as that observed following a single injection of morphine in naive rats (compare with day 1 , filled diamonds, in Figures 1a and b). These findings concur with those of experiment 3 , where it was revealed that the VP did not show evidence of sensitization following a 3 day withdrawal (see Figures $5 \mathrm{c}$ and $\mathrm{d}$ ), and thus, the VP would not likely contribute to the sensitized behaviors evoked by i.p. morphine at this withdrawal time. Another contributing factor to these negative outcomes may be the i.p. dose of morphine selected, for $10 \mathrm{mg} / \mathrm{kg}$ i.p. morphine induced an initial cataleptic-like effect (see Figure 1c), which may have masked hyperlocomotion evoked by intra-VP morphine. Thus, we determined that the question of VP morphine cross-sensitization to systemic morphine would be best addressed by (1) evaluating a protracted withdrawal time that better reflects an involvement of the VP, ie at 14 days withdrawal and (2) using an i.p. dose of morphine that increased locomotion but did not readily evoke catalepsy. A pilot study indicated that $5 \mathrm{mg} / \mathrm{kg}$ i.p. morphine met our criteria, and as shown in Figures $7 \mathrm{c}$ and $\mathrm{d}$, this dose of morphine generally increased motor activity in rats that 
Day 1-5 Treatment: VP MORPHINE
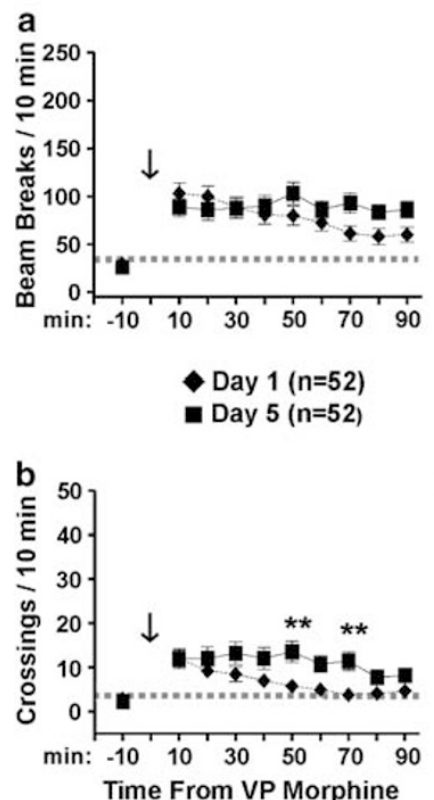

Injection

\section{Challenge: VP MORPHINE}

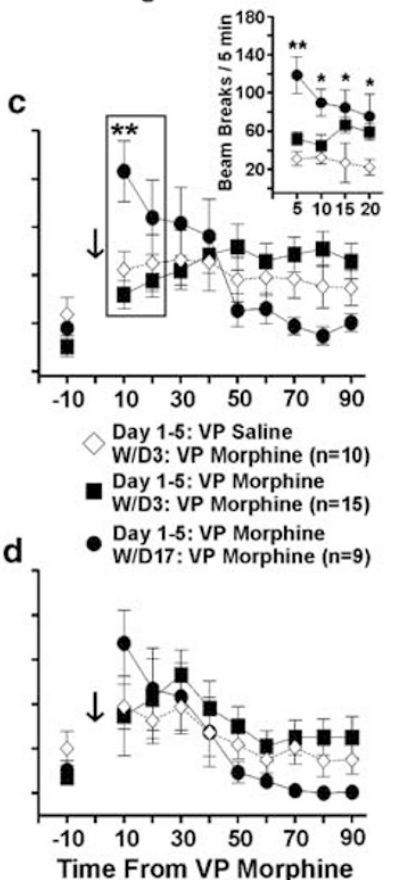

Challenge
Figure 5 (Experiment 3) Sensitization to intraventral pallidal (VP) morphine injections. Development of sensitization was not revealed during the days $1-5$ treatment but was demonstrated by expression of sensitized responding to a VP morphine challenge. Data are provided in I0-min bins; arrow indicates the time of intra-VP injection. Left column. There was no statistical difference between days I and 5 of the saline treatment; these data were averaged and are illustrated by the gray dotted line. Repeated morphine treatments ( $5 \mu \mathrm{g}$ per $0.5 \mu \mathrm{l}$ per side) revealed no statistical differences between treatment day, across session time, or for a treatment day-time interaction for beam breaks (a). For crossings (b) there were significant treatment day $\left(F_{1,102}=6.8, p=0.0103\right)$ and session time $\left(F_{8,816}=4.7, p<0.000 \mathrm{I}\right)$ effects, but no treatment day-time interaction $\left(F_{8,816}=1.6, p=0.1221\right)$. Right column. Behavioral sensitization was expressed following a challenge of intra-VP morphine on withdrawal day 17 (WDI7), but not WD3. (c) Beam breaks. There was no treatment group effect $\left(F_{2,31}=0.1, p=0.89 \mid 9\right)$, but a significant effect of session time $\left(\mathrm{F}_{8,248}=4.9, \quad p<0.000 \mathrm{I}\right)$ and a treatment group-time interaction $\left(F_{16,248}=6.4, p<0.000 \mathrm{I}\right)$ occurred. Inset. Enhanced resolution of early behaviors evoked by intra-VP morphine injections. The boxed portion of the beam breaks graph in 5-min bins for the subset of rats where this time resolution was used (VP saline $(n=5)$, VP morphine W/D3 $(n=7)$, VP morphine W/DI7 $(n=9))$ is shown. There was a significant treatment group $\left(F_{2,18}=5.2\right)$ effect, but no difference across session time $\left(F_{3,54}=1.6\right)$ or a treatment group-time interaction $\left(F_{3,54}=1.5\right)$. Specific session time differences between the VP saline-treated rats and the VP morphinetreated rats only occurred for W/DI7. (d) Crossings. No statistical differences occurred between treatment groups, across session time, or for treatment group-time interactions. $* p<0.05$ and ${ }^{*} * p<0.01$.

received repeated treatments of intra-VP saline. The response was enhanced following 14 days of drug abstinence in rats that received repeated treatments with intraVP morphine (Figure 7c). The number of crossings was not altered. These results indicate that repeated activation of the $\mu$-opioid receptors in the VP initiates adaptive processes that are revealed 2 weeks later upon activation either with motor enhancing doses of systemically administered or intra-VP injected morphine. We then reasoned that i.p. treatments of morphine should sensitize the VP (as predicted by our prior biochemical and electrophysiological
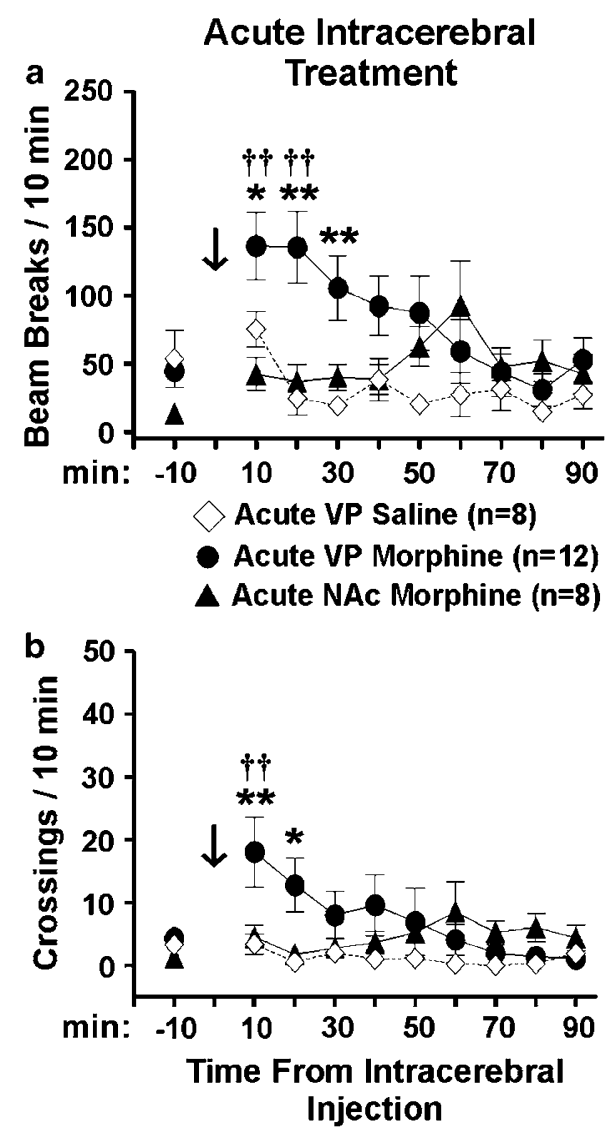

Figure 6 (Experiment 3) Injection site controls. Different profiles were obtained when morphine ( $5 \mu \mathrm{g}$ per $0.5 \mu \mathrm{l}$ per side) was injected into the NAc vs the VP. Data are provided in 10-min bins; arrow indicates time of intracerebral injection. The injector placement is illustrated in Figure 3; VP data were also included in Figure 5. A two-way repeated measures ANOVA was performed among treatment groups. (a) Beam breaks. There were significant treatment group $\left(F_{2,25}=3.4, p=0.0496\right)$ and session time $\left(F_{8,200}=3.6, p=0.007\right)$ effects, and a treatment group-time interaction $\left(F_{\mid 6,200}=3.5, p<0.000 \mathrm{I}\right)$. (b) Crossings. There was no treatment group $\left(F_{2,25}=1.97, p=0.1559\right)$ effect; significant differences occurred for session time $\left(F_{8,200}=1.99, p=0.0487\right)$ with a treatment group-time interaction $\left(F_{16,200}=2.4, p=0.0027\right)$. Specific time differences between intra-VP morphine and intra-VP saline; $* p<0.05$; $* * p<0.01$. Specific time differences between intra-VP morphine and intra-NAc morphine; $\dagger^{\dagger} p<0.01$.

evaluations (McDaid et al, 2006)), and this effect may be revealed by an increase in motor activity following intra-VP injections of the opiate. Figure 8 provides results from the experiment that evaluated this possibility. Motor responses to a challenge of intra-VP morphine 14 days after five oncedaily treatments of $10 \mathrm{mg} / \mathrm{kg}$ i.p. morphine are shown. Both beam breaks and crossings were upregulated within the first 20 min of the intracerebral injection in rats with a treatment history of i.p. morphine; in contrast to repeated intra-VP morphine, where only beam breaks were sensitized. These data indicate that i.p. morphine sensitized brain regions which regulate locomotion that were not affected with repeated intra-VP morphine treatments, but which were subsequently engaged by the intra-VP morphine challenge (refer to Figures $7 \mathrm{c}$ and $\mathrm{d}, 8$ ). In sum, experiment 4 demonstrated that at the 14 day withdrawal period, when intra-VP injections of morphine result in expression of 


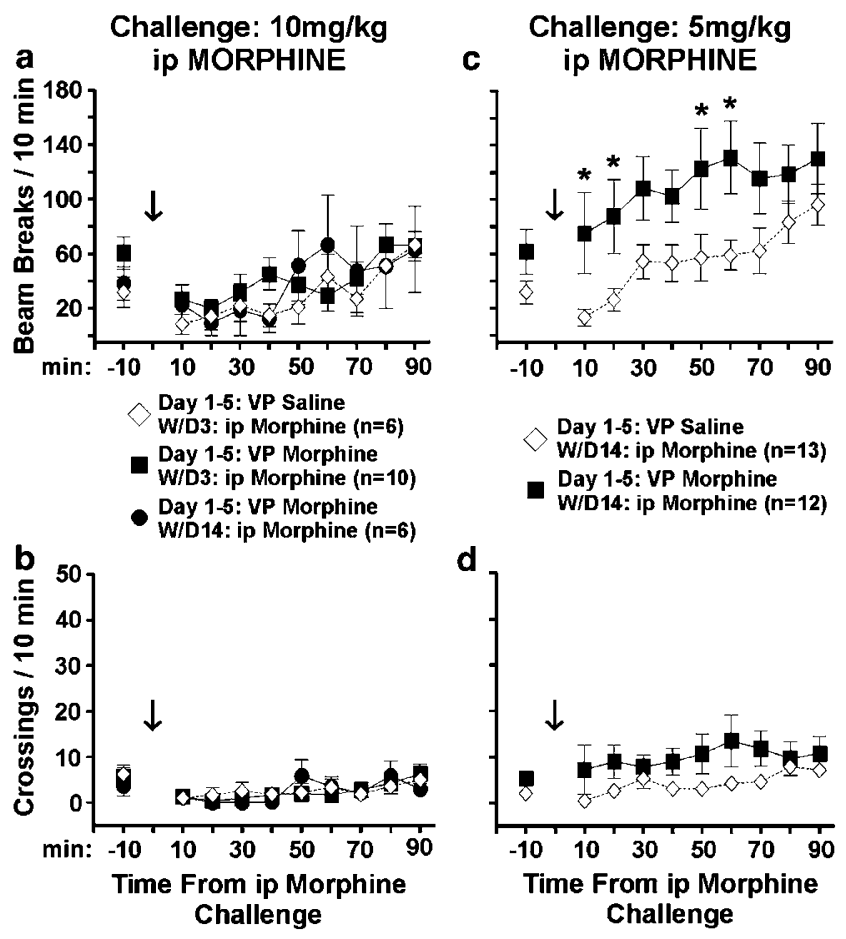

Figure 7 (Experiment 4) Cross-sensitization between intra-VP and systemic morphine treatments. Morphine was administered systemically as $5 \mathrm{mg} / \mathrm{kg}$ or $10 \mathrm{mg} / \mathrm{kg}$ i.p. following a 3- or 14-day withdrawal period from repeated intra-VP treatments of morphine ( $5 \mu \mathrm{g}$ per $0.5 \mu \mathrm{l}$ per side) or saline $(0.5 \mu \mathrm{l}$ per side). Data are provided in I0-min bins; arrow indicates time of i.p. challenge. Left column. Intra-VP injections of morphine did not cross-sensitize with systemic morphine treatments of $10 \mathrm{mg} / \mathrm{kg}$. No statistical differences occurred between the three treatment groups, across session time, or treatment group-time interactions at any time points for (a) beam breaks or (b) crossings. Right column. Intra-VP injections of morphine cross-sensitized with a challenge injection of systemic morphine treatments of $5 \mathrm{mg} / \mathrm{kg}$ after 14 days. (c) Beam breaks. There were significant treatment group $\left(F_{1,23}=5.8, p=0.0241\right)$ and session time $\left(F_{8,184}=5.3, p<0.0001\right)$ effects, but no treatment group-time interaction $\left(F_{8,184}=0.5, \quad p=0.868\right)$. (d) Crossings. There were no significant differences between treatment groups, across time, or treatment grouptime interactions. Specific time differences; ${ }^{*} p<0.05$.

sensitized motor responding, cross-sensitization between systemic and intra-VP injections of morphine can be demonstrated.

\section{DISCUSSION}

The present study revealed four novel findings that modify current concepts of brain circuits underlying drug-induced behavioral sensitization: First, selective activation of $\mu$-opioid receptors within the VP was sufficient to develop behavioral sensitization. Second, blockade of VP $\mu$-opioid receptors prevented the development and expression of sensitization, indicating that these receptors were necessary for both phases of the behavior. Third, infusions of morphine directly into the VP promoted responding to systemic morphine administration, and systemic pretreatments enhanced responding to intra-VP morphine. Fourth, the effects were independent of environmental context, and thus, pharmacological in nature. These results indicate that
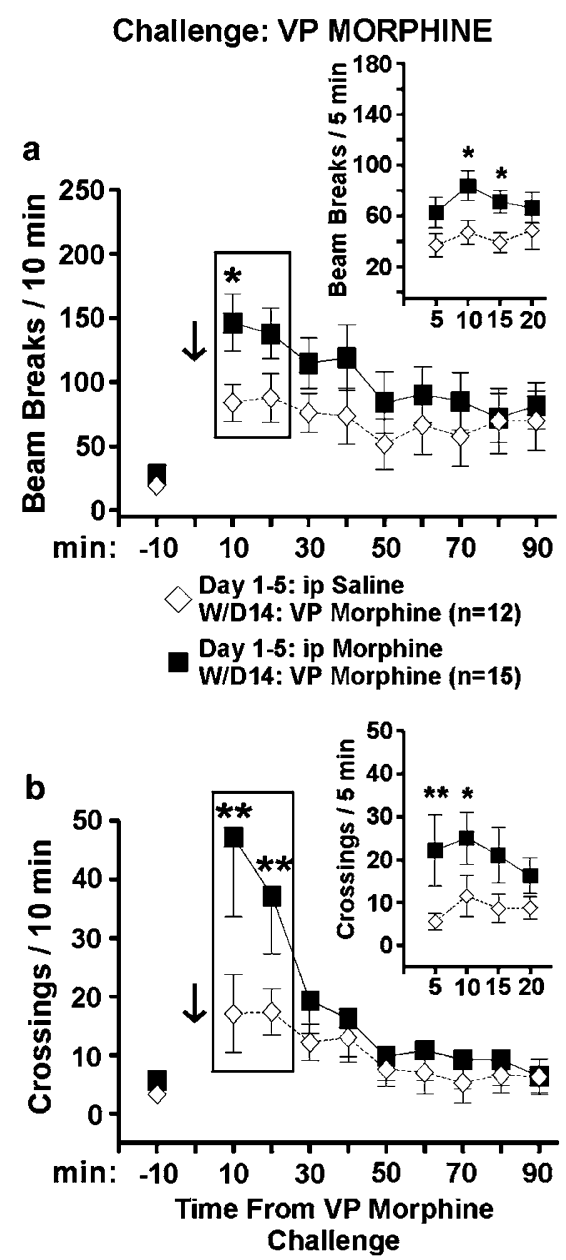

Figure 8 (Experiment 4) Systemic injections of morphine crosssensitized with intra-VP morphine treatments. Data are provided in 10min bins; arrow indicates time of intra-VP challenge. (a) Beam breaks revealed no differences for treatment group $\left(F_{1,22}=1.8, p=0.1919\right)$, but significant session time differences $\left(F_{8,176}=4.0, p=0.0002\right)$. There was no treatment group-time interaction $\left(F_{8,176}=1.05, p=0.3992\right)$. Inset. Enhanced resolution of early behaviors evoked by intra-VP injections of morphine. Data shown represent the boxed portion of the beam breaks graph in 5-min bins. Treatment groups were different $\left(F_{1,22}=4.9\right.$, $p=0.0374)$, but there was no effect of session time $\left(F_{3.66}=1.5\right.$, $p=0.228)$ or a treatment group-time interaction $\left(F_{3,66}=0.6\right.$, $p=0.6105)$. (b) Crossings showed no treatment group effect $\left(F_{1,22}=2.0, \quad p=0.1669\right)$, but a significant difference across time $\left(F_{8,176}=9.3, \quad p<0.0001\right)$ and a treatment group-time interaction $\left(F_{8,176}=2.7, p=0.0083\right)$ was obtained. Inset. Enhanced resolution of early behaviors evoked by intra-VP injections of morphine. No statistical differences occurred between treatment groups, across time or treatment group-time interactions at any time points. Specific time differences; * $p<0.05$; ** $p<0.01$.

VP $\mu$-opioid receptors are critically involved in the neuroadaptive processes that contribute to the development and expression of opiate-induced motor sensitization.

Several experimental considerations serve to buttress these interpretations: (1) Behavioral responding to intracerebral injections reflected action within the VP. The motor response of acute VP morphine was significantly greater than that obtained with similar infusions into the NAc, verifying that motor enhancements following intra-VP injections were not due to the diffusion of morphine into 
this nearby site (Moskowitz and Goodman, 1984). (2) Responding to intra-VP morphine reflected actions at the $\mu$-opioid receptor. The partial agonist alkaloid, morphine and the full agonist peptide, DAMGO, induced similar behavioral effects, and effects to systemic morphine were blocked by intra-VP injections of the $\mu$-opioid antagonist, CTOP. (3) Comparisons of cross-sensitization between i.p. morphine and intra-VP morphine were conducted during the time frame (ie 17 days withdrawal) in which sensitization to morphine was maintained. This claim is substantiated by the findings that the i.p. morphine treatment paradigm used in the current study results in motor sensitization at 3- (Johnson and Napier, 2000), 14- (McDaid et al, 2006), and 30 days of withdrawal (current study). (4) The reacclimation period was sufficient to negate contribution of environmental cues to the morphine-induced motor response. When the context in which the animal receives an opiate (ie the unconditioned stimulus) is unique to the drug experience, the context gains significance with repeated drug pairings, and the behavioral outcome can reflect stimuli-related effects of context as well as the drug effects (Badiani et al, 2000). To isolate drug effects, an extensive habituation to the treatment protocol before pairing is used to remove any contribution of the environmental/procedural context to the measured motor response (Johnson and Napier, 2000; current study). (5) Development and expression of morphine-induced sensitization occurred in rats implanted with cannulae above the VP. Qualitative assessment of gliosis around the injection site (Figure 3a) from implanted rats showed no difference between VP morphine and vehicle treatment groups. The opiate-treated rats developed sensitization (Figures $4 \mathrm{a}$ and $\mathrm{b}$ ) that was expressed following a challenge with intra-VP morphine (Figure 5c) or systemic morphine (Figure 7c). Thus, the amount of gliosis present at the injection site was not sufficient to impede opiate-induced sensitization. Collectively, these controls support the conclusion that VP $\mu$-opioid receptors are important in the development and expression of opiate-induced motor sensitization.

Insight can be gained about the role of the VP in opioidinduced motor sensitization by comparing the behavioral response profile obtained with intra-VP injections of morphine to that obtained with injections into other brain regions, and to systemic morphine treatments. Acute systemic administration of moderate morphine doses induces a biphasic motor response consisting of an initial depression of motor activity followed by hypermotility (Babbini and Davis, 1972; current study). Acute intra-NAc injection of morphine in doses similar to that used in the current experiment also produces motor depression/catalepsy followed by hypermotility (Costall et al, 1978). In contrast, acute administration of opioids into the VTA results only in hypermotility (Kelley et al, 1980; Joyce and Iversen, 1979; Kalivas et al, 1983) as do acute intra-VP opioid injection (Baud et al, 1988; Austin and Kalivas, 1990; Napier, 1992; Alesdatter and Kalivas, 1993; Churchill and Kalivas, 1999; Johnson et al, 1996; current study). With repeated systemic administration of opiates, the initial motor depression is attenuated (likely reflecting tolerance to the cataleptic effects of morphine) and overall activity is robustly increased (ie sensitized) (Babbini and Davis, 1972; Babbini et al, 1975; Brady and Holtzman, 1981; Bartoletti et al, 1983; Johnson and Glick, 1993; current study). Multiple infusions of opioids into the NAc (Vezina et al, 1987; Cunningham et al, 1997), VTA (Joyce and Iversen, 1979; Vezina and Stewart, 1984; Kalivas et al, 1985; Vezina et al, 1987) and VP (present study), all result in hyperlocomotion, but as discussed below, the temporal nature of this effect differs among the regions.

Motor sensitization can be induced (developed) in the VTA, and it can be expressed with a VTA opioid challenge following short-term withdrawal (Kalivas et al, 1985; Vezina et al, 1987). This transient phenomenon is transferred to the NAc that mediates the persistence of this behavior (for review, see Vanderschuren and Kalivas, 2000). The VP is unique in that it is involved in both phases. We previously revealed that the VP is involved in the development of morphine-induced motor sensitization (Johnson and $\mathrm{Na}-$ pier, 2000). The present results confirmed this finding and are the first to demonstrate that this region also is involved in expression of this behavior. We report that activation of $\mu$-opioid receptors in the VP, similar to the VTA, was sufficient to induce a sensitized behavioral response. But the VP distinguishes itself from the VTA in that the progressive increase in motor activity seen during repeated intra-VTA opioids was not obtained during repeated intraVP treatment. We also reveal that a sensitized motor response is not expressed upon intra-VP morphine challenge after 3 days withdrawal, a response that is obtained with opioid activation of the VTA. In these respects, the behavioral response elicited from repeated intra-VP morphine is similar to intra-NAc infusions of morphine or DAMGO, where sensitization is not expressed following short-term withdrawal (Vezina et al, 1987). In addition, we reveal here that a sensitized motor response can be expressed upon intra-VP morphine challenge after long-term (17 days) withdrawal. These results suggest the VP is sufficient for the initiation of enduring adaptations that result in the expression of opioid-induced sensitization.

A commonly accepted theory of behavioral sensitization is that the mesolimbic dopamine system mediates this behavior. Dopamine is a moderately abundant neurotransmitter in the VP (Napier and Potter, 1989; Zaborszky et al, 1993), and it has widespread influence on VP function (Maslowski and Napier, 1991; Napier et al, 1991b). VP opioids regulate local dopamine transmission (for review, see Napier and Mitrovic, 1999), and dopamine receptors in the VP are obligatory for acute motor function mediated by intra-VP $\mu$-opioid receptors (Napier, 1992). Locally applied morphine typically enhances VP neuronal activity (Johnson and Napier, 1997; McDaid et al, 2006), reflecting an inhibition of GABAergic inputs from the NAc (Chrobak and Napier, 1993; Johnson and Napier, 1997) and/or dopaminergic inputs from the VTA (Mitrovic and Napier, 2002). In turn, the VP sends GABAergic outputs to the NAc (Hakan et al, 1992) and VTA (Fonnum et al, 1978; Kalivas et al, 1993) that regulate the number of VTA neurons that are able to exist in an active, spiking mode (Floresco et al, 2003). The VTA provides dopaminergic inputs to the NAc (Fallon and Moore, 1978; Haglund et al, 1979; Swanson, 1982) and VP (Napier et al, 1991a; Klitenick et al, 1992; Mitrovic and Napier, 2002). Dopamine overflow in the NAc core occurs during expression of morphine-induced sensitization following long-term withdrawal (Cadoni and 
Di Chiara, 1999) and intra-VP morphine increases dopamine neurotransmission in the NAc (Anagnostakis and Spyraki, 1994). In light of this literature, the present findings indicate that sensitization-induced changes in VP $\mu$-opioid receptor function reduces GABAergic inhibition of VP GABAergic control over the VTA, leading to an increased number of active dopamine neurons in the VTA and increasing dopamine concentration and receptor activation in the NAc and VP. Like the NAc (Costall and Naylor, 1975) dopamine receptor activation in VP (Napier and Chrobak, 1992) enhances motor function. Thus, the current findings reveal a means by which the VP contributes to the sensitization process.

It is important to note that there is a dopamineindependent component of opioid-mediated behaviors. Acute injections of opioid agonists into the NAc increase motor activity that is not blocked by neuroleptics or 6-OHDA-induced lesions of the NAc (Pert and Sivit, 1977; Kalivas et al, 1983). Studies of opiate-motivated reward reveal that lesions of the NAc do not affect self-administration of morphine (Dworkin et al, 1988). Sensitization induced by chronic systemic administration of morphine is attenuated, but not prevented by lesions of the NAc or VTA (Bunney et al, 1984) or by antagonism of VP dopamine receptors (Johnson and Napier, 2000). One potential site that may be included in the neural adaptations engendered by chronic opiate exposure is the mediodorsal thalamus. This region receives projections from the VP (Young et al, 1984; Vives and Mogenson, 1985) and connects to the motor systems (Groenewegen, 1988; Berendse et al, 1992). Inactivation of the mediodorsal thalamus by procaine prevents the motor responses to acute intra-VP opioid treatment, and acute injections of opioids into the mediodorsal thalamus result in motor activation that remains intact with inhibition of the VTA (Klitenick and Kalivas, 1994). Thus, sensitization-induced enhancements in VP $\mu$-opioid receptor function could also reduce GABAergic inhibition of VP GABAergic influences on the medial dorsal nucleus, and this disinhibition would be predicted to increase thalamic excitatory outputs to hindbrain motor systems. Additional studies are needed to verify whether the mediodorsal thalamic nucleus is involved in sensitization processes.

Glutamate transmission is also involved in opiateinduced sensitization. In the VP, ionotropic glutamate receptors are functionally upregulated 14 days after a sensitizing regimen of morphine (McDaid et al, 2006), and intra-VP injections of glutamatergic antagonists in morphine-sensitized rats block the expression of motor sensitization to a subsequent challenge of i.p. morphine (Dallimore et al, 2006). Thus, a tonic activation of VP glutamatergic receptors appears important to the enduring effects of repeated morphine exposure. Glutamatergic inputs to the VP arise largely from the basolateral amygdala (Russchen and Price, 1984; Fuller et al, 1987) and medial subthalamic nucleus (Kita and Kitai, 1987; Smith and Parent, 1988). The subthalamic nucleus is regulated by $\mu$-opioid agonists (Shen and Johnson, 2002), but it is not known if these become sensitized with repeated activation. However, the basolateral amydgala demonstrates enhancements in receptor-mediated signaling cascades (ie MAPK) in morphine-sensitized rats (Eitan et al, 2003). Thus, it is possible that a sensitized glutamatergic drive to the VP is associated with morphine-induced behavioral sensitization.

In summary, the current study revealed that activation of $\mu$-opioid receptor in the VP are sufficient and necessary to induce a sensitized locomotor response to morphine and that cross-sensitization occurs between morphine treatments given systemically and directly into the VP. As we further elucidate the brain regions that underlie the neuroadaptations associated with repeated drug exposure, we are learning that the major circuit may not be confined to the VTA-NAc corridor, and redundant systems are involved in the various phases of drug-induced sensitization. We propose that the VP is one of the critical neuroanatomical substrates mediating drug-induced sensitization.

\section{DISCLOSURE/CONFLICT OF INTEREST}

The author(s) declare that, except for income received from the primary employer, no financial support or compensation has been received from any individual or corporate entity over the past 3 years for research or professional service and there are no personal financial holdings that could be perceived as constituting a potential conflict of interest.

\section{ACKNOWLEDGEMENTS}

This work was supported by Loyola University Chicago Graduate School, and United States Public Health Grants DA05255 to TCN and DA019783 to ALM and TCN.

\section{REFERENCES}

Alesdatter JE, Kalivas PW (1993). Inhibition of mu opioid-induced motor activity in the ventral pallidum by $\mathrm{D} 1$ receptor blockade. Behav Pharmacol 4: 645-651.

Anagnostakis Y, Spyraki C (1994). Effect of morphine applied by intrapallidal microdialysis on the release of dopamine in the nucleus accumbens. Brain Res Bull 34: 275-282.

Austin MC, Kalivas PW (1990). Enkephalinergic and GABAergic modulation of motor activity in the ventral pallidum. J Pharmacol Exp Ther 252: 1370-1377.

Babbini M, Davis WM (1972). Time-dose relationships for locomotor activity effects of morphine after acute or repeated treatment. Br J Pharmacol 46: 213-224.

Babbini M, Gaiardi M, Bartoletti M (1975). Persistence of chronic morphine effects upon activity in rats 8 months after ceasing the treatment 32. Neuropharmacology 14: 611-614.

Badiani A, Leone P, Stewart J (1995). Intra-VTA injections of the mu-opioid antagonist CTOP enhance locomotor activity. Brain Res 690: 112-116.

Badiani A, Oates MM, Robinson TE (2000). Modulation of morphine sensitization in the rat by contextual stimuli. Psychopharmacology (Berl) 151: 273-282.

Bartoletti M, Gaiardi M, Gubellini G, Bacchi A, Babbini M (1983). Long-term sensitization to the excitatory effects of morphine. A motility study in post-dependent rats. Neuropharmacology 22: 1193-1196.

Baud P, Mayo W, Le Moal M, Simon H (1988). Locomotor hyperactivity in the rat after infusion of muscimol and [DAla2]Met-enkephalin into the nucleus basalis magnocellularis. Possible interaction with cortical cholinergic projections. Brain Res 452: 203-211. 
Berendse HW, Galis-de Graaf Y, Groenewegen HJ (1992). Topographical organization and relationship with ventral striatal compartments of prefrontal corticostriatal projections in the rat. J Comp Neurol 316: 314-347.

Brady LS, Holtzman SG (1981). Locomotor activity in morphinedependent and post-dependent rats. Pharmacol Biochem Behav 14: $361-370$.

Bunney WC, Massar VJ, Pert A (1984). Chronic morphine-induced hyperactivity in rats is altered by nucleus accumbens and ventral tegmental lesions. Psychopharmacology (Berl) 82: 318-321.

Cadoni C, Di Chiara G (1999). Reciprocal changes in dopamine responsiveness in the nucleus accumbens shell and core and in the dorsal caudate-putamen in rats sensitized to morphine. Neuroscience 90: 447-455.

Chrobak JJ, Napier TC (1993). Opioid and GABA modulation of accumbens-evoked ventral pallidal activity. J Neural Trans 93: 123-143.

Churchill L, Kalivas PW (1999). The involvement of the mediodorsal nucleus of the thalamus and the midbrain extrapyramidal area in locomotion elicited from the ventral pallidum. Behav Brain Res 104: 63-71.

Costall B, Fortune DH, Naylor RJ (1978). The induction of catalepsy and hyperactivity by morphine administered directly into the nucleus accumbens of rats. Eur J Pharmacol 49: 49-64.

Costall B, Naylor RJ (1975). The behavioural effects of dopamine applied intracerebrally to areas of the mesolimbic system. Eur J Pharmacol 32: 87-92.

Cunningham ST, Finn M, Kelley AE (1997). Sensitization of the locomotor response to psychostimulants after repeated opiate exposure: role of the nucleus accumbens. Neuropsychopharmacology 16: 147-155.

Dallimore JE, Mickiewicz AL, Napier TC (2006). Intra-ventral pallidal glutamate antagonists block expression of morphineinduced place preference. Behav Neurosci 120: 1103-1114.

Dworkin SI, Guerin GF, Co C, Goeders NE, Smith JE (1988). Lack of an effect of 6-hydroxydopamine lesions of the nucleus accumbens on intravenous morphine self-administration. Pharmacol Biochem Behav 30: 1051-1057.

Eitan S, Bryant CD, Saliminejad N, Yang YC, Vojdani E, Keith Jr D et al. (2003). Brain region-specific mechanisms for acute morphine-induced mitogen-activated protein kinase modulation and distinct patterns of activation during analgesic tolerance and locomotor sensitization. J Neurosci 23: 8360-8369.

Fallon JH, Moore RY (1978). Catecholamine innervation of the basal forebrain. IV. Topography of the dopamine projection to the basal forebrain and neostriatum. J Comp Neurol 180: $545-580$

Floresco SB, West AR, Ash B, Moore H, Grace AA (2003). Afferent modulation of dopamine neuron firing differentially regulates tonic and phasic dopamine transmission. Nat Neurosci 6: 968-973.

Fonnum F, Gottesfeld Z, Grofova I (1978). Distribution of glutamate decarboxylase, choline acetyltransferase and aromatic amino acid decarboxylase in the basal ganglia of normal and operated rats. Evidence for striatopallidal, striatoentopeduncular and striatonigral GABAergic fibers. Brain Res 143: 125-138.

Fuller TA, Russchen FT, Price JL (1987). Sources of presumptive glutamergic/aspartergic afferents to the rat ventral striatopallidal region. J Comp Neurol 258: 317-338.

Groenewegen HJ (1988). Organization of the afferent connections of the mediodorsal thalamic nucleus in the rat, related to the mediodorsal-prefrontal topography. Neuroscience 24: 379-431.

Haglund L, Kohler C, Ross SB, Kelder D (1979). Forebrain projections of the ventral tegmentum as studied by axonal transport of $[3 \mathrm{H}]$ dopamine in the rat. Neurosci Lett 12: 301-306.

Hakan RL, Berg GI, Henriksen SJ (1992). Electrophysiological evidence for reciprocal connectivity between the nucleus accumbens septi and ventral pallidal region. Brain Res 581: 344-350.

Johnson DW, Glick SD (1993). Dopamine release and metabolism in nucleus accumbens and striatum of morphine-tolerant and nontolerant rats. Pharmacol Biochem Behav 46: 341-347.

Johnson K, Churchill L, Klitenick MA, Hooks MS, Kalivas PW (1996). Involvement of the ventral tegmental area in locomotion elicited from the nucleus accumbens or ventral pallidum. J Pharmacol Exp Ther 277: 1122-1131.

Johnson PI, Napier TC (1997). Morphine modulation of GABAand glutamate-induced changes of ventral pallidal neuronal activity. Neuroscience 77: 187-197.

Johnson PI, Napier TC (2000). Ventral pallidal injections of a mu antagonist block the development of behavioral sensitization to systemic morphine. Synapse 38: 61-70.

Joyce EM, Iversen SD (1979). The effect of morphine applied locally to mesencephalic dopamine cell bodies on spontaneous motor activity in the rat. Neurosci Lett 14: 207-212.

Kalivas PW, Churchill L, Klitenick MA (1993). GABA and enkephalin projection from the nucleus accumbens and ventral pallidum to the ventral tegmental area. Neuroscience 57: 1047-1060.

Kalivas PW, Taylor S, Miller JS (1985). Sensitization to repeated enkephalin administration into the ventral tegmental area of the rat. I. Behavioral characterization. J Pharmacol Exp Ther 235: 537-543.

Kalivas PW, Widerlov E, Stanley D, Breese G, Prange Jr AJ (1983). Enkephalin action on the mesolimbic system: a dopaminedependent and a dopamine-independent increase in locomotor activity. J Pharmacol Exp Ther 227: 229-237.

Kelley AE, Stinus L, Iversen SD (1980). Interactions between Dala-met-enkephalin, A10 dopaminergic neurones, and spontaneous behaviour in the rat. Behav Brain Res 1: 3-24.

Kita H, Kitai ST (1987). Efferent projections of the subthalamic nucleus in the rat: light and electron microscopic analysis with the PHA-L method. J Comp Neurol 260: 435-452.

Klitenick MA, Deutch AY, Churchill L, Kalivas PW (1992). Topography and functional role of dopaminergic projections from the ventral mesencephalic tegmentum to the ventral pallidum. Neuroscience 50: 371-386.

Klitenick MA, Kalivas PW (1994). Behavioral and neurochemical studies of opioid effects in the pedunculopontine nucleus and mediodorsal thalamus. J Pharmacol Exp Ther 269: 437-448.

Li Y, Kolb B, Robinson TE (2003). The location of persistent amphetamine-induced changes in the density of dendritic spines on medium spiny neurons in the nucleus accumbens and caudate-putamen. Neuropsychopharmacology 28: 10821085.

Maslowski RJ, Napier TC (1991). Dopamine D1 and D2 receptor agonists induce opposite changes in the firing rate of ventral pallidal neurons. Eur J Pharmacol 200: 103-112.

Maslowski-Cobuzzi RJ, Napier TC (1994). Activation of dopaminergic neurons modulates ventral pallidal responses evoked by amygdala stimulation. Neuroscience 62: 1103-1120.

McDaid J, Dallimore JE, Mackie A, Napier TC (2006). Changes in accumbal and ventral pallidal pCREB and deltaFosB in morphine-sensitized rats: correlations with receptor-evoked electrophysiological measures in the ventral pallidum. Neuropsychopharmacology 31: 1212-1226.

Mitrovic I, Napier TC (2002). Mu and kappa opioid agonists modulate ventral tegmental area input to the ventral pallidum. Eur J Neurosci 15: 257-268.

Mogenson GJ, Yang CR (1991). The contribution of basal forebrain to limbic-motor integration and the mediation of motivation to action. In: Napier TC, Kalivas PW, Hanin I (eds). The Basal Forebrain: Anatomy to Function. Plenum Press: New York and London. pp 267-290. 
Moskowitz AS, Goodman RR (1984). Light microscopic autoradiographic localization of $\mathrm{mu}$ and delta opioid binding sites in the mouse central nervous system. J Neuroscience 4: 1331-1342.

Napier TC (1992). Dopamine receptors in the ventral pallidum regulate circling induced by opioids injected into the ventral pallidum. Neuropharmacology 31: 1127-1136.

Napier TC, Chrobak JJ (1992). Evaluations of ventral pallidal dopamine receptor activation in behaving rats. Neuroreport 3: 609-611.

Napier TC, Mitrovic I (1999). Opioid modulation of ventral pallidal inputs. Ann NY Acad Sci 877: 176-201.

Napier TC, Muench MB, Maslowski RJ, Battaglia G (1991a). Is dopamine a neurotransmitter within the ventral pallidum/ substantia innominata. Adv Exp Med Biol 295: 183-195.

Napier TC, Potter PE (1989). Dopamine in the rat ventral pallidum/ substantia innominata: biochemical and electrophysiological studies. Neuropharmacology 28: 757-760.

Napier TC, Simson PE, Givens BS (1991b). Dopamine electrophysiology of ventral pallidal/substantia innominata neurons: comparison with the dorsal globus pallidus. J Pharmacol Exp Ther 258: 249-262.

Paxinos G, Watson C (1998). The Rat Brain in Stereotaxic Coordinates. Academic Press: New York.

Pelton JT, Kazmierski W, Gulya K, Yamamura HI, Hruby VJ (1986). Design and synthesis of conformationally constrained somatostatin analogues with high potency and specificity for mu opioid receptors. J Med Chem 29: 2370-2375.

Pert A, Sivit C (1977). Neuroanatomical focus for morphine and enkephalin-induced hypermotility. Nature 265: 645-647.

Russchen FT, Price JL (1984). Amygdalostriatal projections in the rat. Topographical organization and fiber morphology shown using the lectin PHA-L as an anterograde tracer. Neurosci Lett 47: 15-22.

Shen KZ, Johnson SW (2002). Presynaptic modulation of synaptic transmission by opioid receptor in rat subthalamic nucleus in vitro. J Physiol 541: 219-230.

Shippenberg TS, Bals-Kubik R (1995). Involvement of the mesolimbic dopamine system in mediating the aversive effects of opioid antagonists in the rat. Behav Pharmacol 6: 99-106.

Smith Y, Parent A (1988). Neurons of the subthalamic nucleus in primates display glutamate but not GABA immunoreactivity. Brain Res 453: 353-356.
Swanson LW (1982). The projections of the ventral tegmental area and adjacent regions: a combined fluorescent retrograde tracer and immunofluorescence study in the rat. Brain Res Bull 9: 321-353.

Vanderschuren LJ, Kalivas PW (2000). Alterations in dopaminergic and glutamatergic transmission in the induction and expression of behavioral sensitization: a critical review of preclinical studies. Psychopharmacology (Berl) 151: 99-120.

Vezina P, Kalivas PW, Stewart J (1987). Sensitization occurs to the locomotor effects of morphine and the specific u opioid receptor agonist, DAGO, administered repeatedly to the ventral tegmental area but not to the nucleus accumbens. Brain Res 417: $51-58$.

Vezina P, Stewart J (1984). Conditioning and place-specific sensitization of increases in activity induced by morphine in the VTA. Pharmacol Biochem Behav 20: 925-934.

Vives F, Mogenson GJ (1985). Electrophysiological evidence that the mediodorsal nucleus of the thalamus is a relay between the ventral pallidum and the medial prefrontal cortex in the rat. Brain Res 344: 329-337.

Wolf ME (2002). Addiction: making the connection between behavioral changes and neuronal plasticity in specific pathways. Mol Interv 2: 146-157.

Young WS, Alheld GF, Heimer L (1984). The ventral pallidal projection to the mediodorsal thalamus: a study with fluorescent retrograde tracers and immunohistofluorescence. J Neuroscience 4: 1626-1638.

Zaborszky L, Alheid GF, Heimer L (1985). Mapping of transmitterspecific connections: simultaneous demonstration of anterograde degeneration and changes in the immunostaining patterns induced by lesions. J Neurosci Methods 14: 255-266.

Zaborszky L, Cullinan WE, Luine VN (1993). Catecholaminergiccholinergic interaction in the basal forebrain. In: Cuello AC (ed). Progress in Brain Research. Elsevier Science Publishing Co. Inc: NY, Vol. 98, pp 31-49.

Zahm DS (1989). The ventral striatopallidal parts of the basal ganglia in the rat-II. Compartmentation of ventral pallidal efferents. Neuroscience 30: 33-50.

Zahm DS, Zaborszky L, Alones VE, Heimer L (1985). Evidence for the coexistence of glutamate decarboxylase and met-enkephalin immunoreactivities in axon terminals of rat ventral pallidum. Brain Res 325: 317-321. 